http://jmscr.igmpublication.org/home/ ISSN (e)-2347-176x ISSN (p) 2455-0450

crossref DOI: https://dx.doi.org/10.18535/jmscr/v7i12.48

\title{
Mucin Histochemistry in Normal and Adenocarcinoma of Colorectum- A Comparative Study
}

\author{
Authors \\ Dr Sumana Sindhuram $V^{1}$, Dr Roopashree $\mathbf{G}^{2^{*}}$, Dr Pavan kumar $\mathbf{M}^{3}$
}

${ }^{1}$ Assistant Professor, Department of Pathology, Mysore Medical College and Research Centre, Mysore

${ }^{2}$ Postgraduate Student, Department of Pathology, Mysore Medical College and Research Centre, Mysore

${ }^{3}$ Postgraduate Student, Department of Pathology, Mysore Medical College and Research Centre, Mysore

*Corresponding Author

Dr Roopashree G

Postgraduate Student, Department of Pathology, Mysore Medical College and Research Centre, Mysore

\begin{abstract}
Background: Mucins are complex carbohydrates secreted by different types of epithelial cells and glandular tissues of gastrointestinal tract. Mucins are mainly of two types- Neutral and Acidic. Pathological expression of mucins has been implicated in cancer development and progression.

Objectives

- To know the mucin distribution pattern in normal and malignant lesions of the colon and rectum.

- To differentiate the types of mucin secreted in normal and malignant lesions of the colon and rectum, based on the colour intensity.

Methodology: The present study was conducted on twenty five specimens of each normal and carcinoma of colon and rectum, which were collected from surgically resected, small biopsy specimens and postmortem specimens received in the Department of Pathology, MMC \& RI. Normal colorectal specimens were used as controls with colorectal carcinoma as tests.

Routine $H \& E$ and special stains such as PAS, PAS-Diastase, combined AB-PAS were performed.

Results: Results were tabulated according to colour intensity into different grades ranging from + to ++++. Regarding mucin histochemistry of normal colon - "mixture" of mucins were observed with predominance of "neutral" and "sulphomucins". In colon adeno-carcinoma "sialomucins" were seen predominant than neutral and sulphomucins.

Conclusion: Mucin histochemistry is a valuable and cost-effective tool for determining the types of mucins which is one of the important prognostic marker in early detection of colorectal cancers.

Keywords: Colorectum, adenocarcinomas, mucins, histochemistry, special stain.
\end{abstract}

\section{Introduction}

Colo-rectal cancer is the fourth most commonly diagnosed malignant disease worldwide, with over one million new cases and approximately 500,000 deaths each year ${ }^{1}$.
It is now the fifth most common cause of cancer mortality among Indian men and women. Development and progression of colonic cancers are well associated with abnormal expression of mucins $^{3}$. 
Mucin is a high molecular weight glycoprotein that is synthesized, stored and secreted by the epithelial mucosal cells, especially the goblet cells ${ }^{9}$.

Mucin acts as a lubricant on surfaces to protect them from friction, erosion, and provides a protective barrier against pathogens and toxins thus contributing for innate defensive system in normal colonic tissue ${ }^{12}$. Mucins also play a role in process of tumor progression, invasion and metastasis and also in tumor cell survival and protection against the host immune response ${ }^{13}$.

Mucins are histochemically classified into two types, neutral and acidic mucins. Acidic mucins are further categorized into sulfated and sialomucins ${ }^{9}$. Sulfated muco substances are found in the deeper colonic tissue, where cell division occurs. Sulfated mucins play an important role in control of cell division and decline in the production of which, would predispose colonic mucosa to malignancy ${ }^{5}$.Mucin histochemistry can effectively determine the mucin profile of colorectal adenocarcinoma. Mucin content and type of mucin can be regarded as important prognostic indicator and early diagnosis helps in reducing mortality related to colorectal tumors ${ }^{2}$.

Any stain in general other than $\mathrm{H} \& \mathrm{E}$ stain is regarded as special stain which can identify cell and tissue components by virtue of their specific chemical reactions ${ }^{15,18}$. In the present study, combination of special stains such as P.A.S, Alcian blue were used simultaneously to asses various types of mucins in the epithelium of colon and rectum examined.

\section{Materials and methods}

The present study was conducted in the Department of Pathology, Mysore Medical College and Research Institute, Mysore, during the period of August 2018 - September 2019 (13 months). It is a case control study which is a type of analytical study.

The study was carried out on 25 specimens of each normal and carcinoma colon, collected from surgically resected, small biopsy specimens and post mortem specimens received in the Department of Pathology, MMC \& RI. Normal colorectal specimens will be used as controls with colorectal carcinoma as tests.

Tissue specimens were fixed in $10 \%$ neutral buffered formalin which helps for preservation of mucins. In every case standard protocol of surgical grossing was followed. Tissues were embedded in paraffin blocks and by using histopathological technique 5-6 $\mu \mathrm{m}$ thick sections were cut for routine HE (Hematoxylin-Eosin) staining.

In addition sections were cut from a paraffin block of tissue and taken on glass slide and special stains such as PAS (Periodic Acid Schiff) were performed to know- general staining of mucins, PAS Diastase (PAS-D) - for confirmation of muco substances, and combined PAS/AB (Periodic Acid Schiff/Alcian Blue) - for determining the nature of mucins (as neutral and acidic) and also to differentiate acidic mucins into sulphomucins and sialomucins.

All the results will be tabulated according to color intensity into different grades ranging from + to ++++ .

\section{Color index:}

1) ++++ : Very strong positive reaction.

2) +++ :Strong positive reaction

3) ++ : Moderate reaction

4) + : Weak reaction

5) - $\quad$ : Negative reaction

\section{Observation and Results}

We included 25 cases of carcinoma colon as test and 25 normal colon as control. Using $\mathrm{H} \& \mathrm{E}$ stain cases of carcinoma colon were categorised into 3 grades well differentiated, moderately differentiated and poorly differentiated. Out of 25 cases of carcinoma colon 3 were well differentiated, 15 were moderately differentiated and 7 were poorly differentiated. On application of PAS stain22 cases of normal colon showed strong positive reaction $(+++)$ and remaining 3 cases showed very strong positive reaction $(++++)$. Among 25 cases of carcinoma colon 18 
cases showed moderate reaction (++) and 7 cases showed weak reaction $(+)$ with PAS stain. PAS-D stain was applied on all 50 cases of carcinoma colon and normal colon specimens and we observed that all cases of normal colon showed very strong positive reaction (++++) and all cases of carcinoma colon showed strong reaction (+++). Thus we concluded that positive reaction showed by PAS stain was due to muco substances and not due to glycogen. Combined PAS and alcian blue stain (AB-PAS) were carried out on all 50 cases to assess neutral and acidic mucins.

Results are summarised in (table1, 2 \& 3). Inference from present study showed regarding mucin histochemistry of normal colon, "mixture" of muco substances were observed. In that predominantly "neutral mucin" and "sulphated acidic mucin" were observed. Regarding mucin histochemistry of carcinoma colon, "mixture of muco substances" were observed, but in contrast to normal colon "carboxylated acidic mucins" were seen predominantly than neutral and sulphated acidic mucins. In present study predominant sulphated acidic mucins (Sulphomucins) were seen in normal colon, whereas loss of sulphation with predominant carboxylated (Sialomucin) was seen in carcinoma colon.

Table no 1. Mucin distribution pattern observed in PAS staining with diastase digestion (PAS with diastase)

\begin{tabular}{|l|c|c|c|c|}
\hline Colour intensity & + & ++ & +++ & ++++ \\
\hline No of controls (25) & - & - & $22(88 \%)$ & $3(12 \%)$ \\
\hline No of cases (25) & $7(28 \%)$ & $18(72 \%)$ & - & - \\
\hline
\end{tabular}

Table no 2. Comparison of expression of carboxylated sialomucin and sulphomucin between cases and controls by combined PAS and alcian blue staining (AB-PAS)

\begin{tabular}{|l|c|c|c|c|c|c|}
\hline Colour intensity & & $(\mathbf{0})$ & + & ++ & +++ & ++++ \\
\hline No of controls (25) & Sialomucin & $20(80 \%)$ & $5(20 \%)$ & - & - & - \\
\hline & Sulphomucin & - & $2(8 \%)$ & $8(32 \%)$ & $15(60 \%)$ & - \\
\hline No of cases (25) & Sialomucin & - & $3(12 \%)$ & $8(32 \%)$ & $14(56 \%)$ & - \\
\hline & Sulphomucin & $5(20 \%)$ & $17(68 \%)$ & $3(12 \%)$ & - & - \\
\hline
\end{tabular}

\section{Discussion}

Mucins are complex carbohydrates secreted by epithelial and connective tissue cells. Mucins are well documented in playing essential physiological roles, including protecting epithelial surfaces against damages ${ }^{4}$, suppressing inflammatory activity by preventing direct exposure of commensal bacteria to the epithelium ${ }^{6}$ and the transmitting information from the external environment to the epithelium referred to as cell signaling ${ }^{7}$. Alterations of the expression pattern of mucins have been described in carcinomas as well as in their precursor lesions ${ }^{10}$. Mucinous carcinoma is a histological variant that accounts for $5 \%$ to $15 \%$ of cases of primary colorectal cancer ${ }^{8}$. Compared with nonmucinous carcinoma, mucinous carcinoma has been known to have a propensity for higher incidence of lymph node metastasis, venous and lymphatic invasions, local recurrence, and distant metastasis ${ }^{9}$. Consequently, the prognosis is worse. Therefore, mucinous carcinomas require more aggressive surgical excision, with wide margins, extensive lymph node dissection, and complete dissection of tumour extending into adjacent structures, than do nonmucinous carcinomas ${ }^{11}$. The PAS technique is the most widely used techniques for the demonstration of glycoproteins, carbohydrates and mucins. The PAS technique is particularly sensitive to the detection of neutral mucins. Diastase digestion followed by PAS was utilized to distinguish the diastase-resistant muco substances from glycogen. The combined alcian blue AB/PAS technique is widely used for the detection and characterization of muco substances in tissue sections. The Alcian blue-PAS technique 
is a simple procedure and appears to differentiate sharply between acidmucins and neutral mucins.

In the present study, the mucin histochemistry of normal adult colon revealed mixture of muco substances as neutral and acidic mucins with predominance of sulphomucins ${ }^{16}$. Carcinoma of colon and rectum showed predominantly acidic mucins with traces ofneutral mucin ${ }^{8}$. In the acidic mucins, predominantly sialomucins were observed as compared to normal colon and rectum ${ }^{17}$. Loss of sulphation in colorectal tumors may be due to reaction to neoplasia by various extracellular and intracellular factors as proposed and hypothesized by various scientists ${ }^{5,14}$.

\section{Conclusion}

Mucin histochemistry may provide a valuable and cost-effective tool for the diagnostic histopathology. Mucin histochemistry can effectively determine the mucin profile of colorectal adenocarcinoma ${ }^{2}$. Mucin content and type of mucin present can be regarded as important prognostic indicator and early diagnosis may help in reducing mortality regarding colorectal tumors.

\section{References}

1. Parkin DM, Bray F, Ferlay J, Pisani P. Global cancer statistics. CA Cancer J Clin 2005;55 (2):74-108.

2. Nikumbh RD, Nikumbh DB, Umarji BN. Mucin histochemical study of the colon in normal and malignant lesions. Int $\mathbf{J}$ Health Sci Res 2012;2(7):20-32.

3. Danquah KO, Adjei E, Quayson S, Adankwah E, Gyamfi D, Ossei PPS et al. Mucin expression patterns in histological grades of colonic cancers in Ghanaian population. Pan African Med Jr 2017; 27 (10):26-27. 5.

4. Rachagani S, Torres MP, Moniaux N, Batra SK. Current status of mucins in the diagnosis and therapy of cancer. Biofactors. 2009; 35(6): 509-527.
5. Subbuswamy SG. Patterns of mucin secretion in human intestinal mucosa. JrAnat 1971; 108 (2):291-93.

6. Kufe DW. Mucins in cancer: function, prognosis and therapy. Nat Rev Cancer. 2009; 9(12): 874-885.

7. Mowry RW. Alcian blue technics for the histochemical study of acidic carbohydrates. J Histochem \& Cytochem. 1956; 4(5): 403-407. 8. Zusman I, Zimber A, Nyska A. Role of morphological methods in the analysis of chemically induced colon cancer in rats. ActaAnat (Basel). 1991; 142(4): 351-356.

8. Ali U, Nagi AH, Naseem N, Ullah E. Mucin Histochemistry in Tumors of Colon, Ovaries and Lung. J Cytol Histol 2012; 3 (7):2157-99.

9. Hakomori S (1989) aberrant glycosylation in tumors and tumor-associated carbohydrate antigens. Adv Cancer Res 52: 257-331.

10. Yamamoto S, Mochizuki H, Hase K (1993) Assessment of clinicopathologic features of colorectal mucinous adenocarcinoma. Am J Surg 166:257-261.

11. CorfieldAp, Shukla AK (2004) Mucins: vital components of the mucosal defensive barrier. Genomic/Proteomic Technol 3: 20-22.

12. Komatsu M, Yee L, Carraway KL (1999) Overexpression of sialomucin complex, a rat homologue of MUC4, inhibits tumor killing by lymphokine-activated killer cells. Cancer Res 59: 2229-2236.

13. Filipe MI, Lake BD, Histochemistry in Pathology, Churchill Livingstone, Edinburgh, 1983, 312.

14. SPICER SS (1965) Diamine methods for differentialing muco substances histochemically. J Histochem Cytochem 13: 211-234.

15. Ganga GM. Study of mucin histochemistry in stomach and large intestine of human fetuses and its comparison with normal 
adult and malignant epithelial tumors of large intestine. PhD Cell Biology, Thesis, Shivaji University, Maharashtra, India, 2003.

16. Gad A. A histochemical study of human alimentary tract mucosubstances in health and disease: Normal and tumors. British Jr Cancer. 1969; 23(1): 52-63.

17. Alan Stevans. The haematoxylin in: Bancroft JD, Stevans A (editors). Theory and practice of histological technique.3rd ed. Churchill Livingstone, New York. 1990: 107117.

18. Awad E, Abdul Raheem EM. Demonstration of mucins in gastrointestinal tract carcinoma lesions in Sudanese patients. Int $\mathbf{J}$ Pure and ApplSciTechnol 2014; 21 (2): 28-31.

19. Mandal PK, Chakrabarti S, Ray A, Chattopadhyay B, Das S. Mucin histochemistry of stomach in metaplasia and adenocarcinoma: An observation. Indian J Med Pediat Oncol 2013;34:22933.

20. Turani H, Lurie B, Chaimoff C, Kessler E. The diagnostic significance of sulfated acid mucin content in gastric intestinal metaplasia with early gastric cancer. Am J Gastroenterol. 1986; 81(5): 343-345. 